\title{
Expanding the Building System into a Product Platform for Improved Design and Manufacture - A Case Study in Industrialised House-Building
}

\author{
Shamnath THAJUDEEN ${ }^{\mathrm{a}, 1}$ Martin LENNARTSSON ${ }^{\mathrm{b}}$ and Fredrik ELGH ${ }^{\mathrm{a}}$ \\ ${ }^{a}$ Department of Industrial Product Development, Production and Design, School of \\ Engineering, Jönköping University, Gjuterigatan 5, 55318 Jönköping, Sweden \\ ${ }^{\mathrm{b}}$ Department of Building Engineering and Lighting Science, School of Engineering, \\ Jönköping, University, Gjuterigatan 5, 55318 Jönköping, Sweden
}

\begin{abstract}
Industrialised house builders in Sweden have been challenged to meet the demand for housing solutions as the population has increased at a faster rate. As a result, the housing industry is currently faced with objectives to improve productivity and internal efficiency while also controlling the production cost of houses without compromising external efficiency. To remain competitive, many companies developed own building system (BS) based on fixed or partially fixed production systems with different prefabrication techniques. The challenges remain in the design phase and proper methods and tools are required to manage it. In many industries, the product platform approach has been used as a means to achieve both internal and external efficiency. However, little attention has been paid in relating the platform approach to building system support in the design phase of Industrialised house building (IHB). Thus, the main purpose of this paper is to explore the current state of the industrialised house building system and outline design support solutions for the building system from a product platform approach. Qualitative research was conducted by linking a single case company working with post and beam building system in combination with a literature review. Empirical data were gathered from five semi-structured interviews and two workshop sections. A cause-effect analysis has been conducted to realize the potential causes of challenges in the design process. The result illustrates a methodology with principle solutions that can be used as design support for the case company as a path forward and improve further from a product platform perspective.
\end{abstract}

Keywords. Industrialised house building, Building system, Product platform, Design phase, Support method.

\section{Introduction}

In Sweden, the demand for housing continues to grow as the population has increased at a faster rate [1] and the supply of housing has been slow down. As a result, the industrialised house building (IHB) industry is currently faced with objectives to focus on improving productivity and internal efficiency while also controlling the

${ }^{1}$ Corresponding Author. shamnath.thajudeen@ju.se 
production costs of homes without jeopardizing external efficiency. The IHB can be defined as "a thoroughly developed building process with a well-suited organization for efficient management, preparation, and control of included activities, flows, resources and results for which highly developed components are used in order to create maximum customer value" [2]. The building systems (BS) is considered as the foundation of continuous improvement in the IHB process [3]. It constitutes of the systematic, controlled and standardized production process, which allows monitoring and gathering experiences of design, production and assembly [4]. To remain competitive in the market, many house building companies developed own building system based on their fixed or partially fixed production settings with different prefabrication techniques by including several supports and tools. Many of these developed systems have evolved over decades and cannot be easily adapted to volatile markets [5]. Moreover, the lack of proper modelling and documentation of the BS makes the system difficult to adapt to unstable customer requirements. The BS is closely related to the design phases and plays a very crucial role in supporting the decision-making in different stages of building design. Consequently, the overall challenges reside in the design phase. Thus, to fulfill customer needs, adapt to technology changes and increase productivity, adequate support is needed for the BS as the project goes through several stages with varying degrees of details.

Tools/techniques are key assets that can support designers to develop products that not only meet the requirements imposed by the market but also allow designers to express their capacities [6]. With the increasing complexity in the design activities, tools/techniques are constantly developed by designers to aid themselves in executing different activities. In house building, there is a custom of using different support methods for design in different projects and these methods are often pragmatic [7]. Various studies $[2,3,8]$ have been conducted on developing support for the IHB aiming to improve productivity. When it comes to improving both internal and external efficiency, the product platform approach has been acknowledged as a promising tool that has proven in many other industries [9, 10]. Jansson [11], proposes the use of a product platform approach in IHB design as a support for day-to-day work. However, studies about the relationship between the building system support for design and the product platform approach seems less where the existing support for design has been explored and evaluated. Thus, the main purpose of this paper is to explore the current state of the Industrialised house building system and outline design support solutions for the building system from a product platform approach. In this paper, a multi-storey house building company with post and beam building system has been studied to outline the existing support and challenges in the design process with the purpose to identify critical gaps and potential areas for improvements. This is followed by further development of the BS to a product platform supported by a coherent description and methods for increased efficiency in both design and manufacture. This is a single case study and the scope is delimited to the timber-based IHB company and positioned in the design.

\section{Theoretical background}

According to Mukkavaara [12], IHB design can span over several stages, where the process usually starts with conceptual design and continues through design development including systems design, and detailed design. Building system for IHB is defined as "the collected experience and knowledge in how to realize a construction project" [3]. It integrates process and proficient knowledge from several domains into one unified 
system which is the combination of a technical and process platform [8]. Thus, a BS can be standardized both in technical solutions and in standardized work [13] and can be categorized based on the customer order decoupling point in the product specification.

The platform approach to product development is considered as a success factor in many industries and markets [9]. Companies achieve high levels of product variety, reduced time to market, better operational efficiency and responsiveness to market needs [14. A product platform comprises four main assets named components, processes, knowledge, and relationships [15]. Component assets consist of part design of the product, tools, and fixtures. The process and equipment used to produce and assemble come under process assets. Knowledge assets include design know-how, technology, applications and limitation, testing models and methods. Relationship asset contains relationships between stakeholders in the process. Platform planning includes a product plan for options, a differentiation plan to make sure that the models differ to attract customers, and a commonality plan that defines where products in the plan share the same physical element (ibid). The practice of reusing processes and technical solutions leads to the formation of product platforms in house building [7]. The technical platform consists of technical and modularized solutions of the building parts of various kinds and the process platform is developed mainly to support the technical platform by providing an adequate definition of the main process in the company [2]. The drive towards mass customization in house-building is possible using the platform [2, 16]. The product variant master (PVM) is a tool that can be used to model a product platform [17]. According to Salvador [18], three fundamental capability of mass customisation is (1) solution space development, that identify the product attributes for customer, (2) robust process design, explains the capability to reuse or recombine existing solutions and (3) choice navigation, that supports customers decision making and to identify suitable solutions while reducing complexity. As a summary, studies that examine the link between product platform and BS in the area of IHB seem limited. Thus, the presented research fills this gap by examining the existing building system support in the design phase of IHB and its relation to the platform from a theoretical and practical perspective.

\section{Research Methodology}

Design Research Methodology (DRM) was used as a research approach for this study, which was proposed by Blessing and Chakrabarti [19]. DRM is a four-stage iterative process used to develop innovative solutions that solve practical problems and allows a theoretical contribution in the engineering design research field. DRM is used as a framework for the whole research project and this paper covers the second and third phases. The literature review and case study have been conducted in the Descriptive Study 1 phase to analyse the current state and followed by the development of a design support framework in the prescriptive study phase. A qualitative study was conducted with a combination of a literature survey and a single case study at one of the Swedish multi-storey house builders. A case study research (CSR) method was chosen as the focus is on a contemporary phenomenon within a real-life context [20].

The empirical data were gathered from semi-structured interviews (five persons) and two workshop sections (seven persons) with the design and management team. Participants in the interview include two structural engineers, a design engineer, a design manager, and the managing director. The quality manager and a CAD engineer also took part in the workshop. The unit of analysis was on the current way of working in the 
design process with special concern in the use of the building system. The first section of the workshop started with brainstorming the major challenges and listed down the root causes of the inefficiencies in the design process. They are then grouped under different categories using a fishbone or cause-effect diagram. During the second section, possible solutions to manage these design challenges were listed and prioritised by ranking them out of five points where critical solutions ranked with higher points. A tree structure has been drawn with all principle solutions under three different categories. The interviews and workshops were audio-recorded and transcribed before the materials were analysed. Parallel to the case study, a literature survey was also initiated to ease the analysis task. A framework was developed with the data gathered from empirical data, i.e., the design support identified from the interviews were categorized under different platform assets. This formulated framework was used for the synthesis and analysis of the results. After the data analysis, a methodology was developed with principle solutions for the improvement of the design process.

\section{Single case study - Design phase}

The case company owns a unique building system in the multi-storey house building market and the system is developed based on timber post $\&$ beam prefabricated technique. The building system was launched in 2007 and can be used for up to an 8-meter free span. The main components of the building system include pillar/post, beams, trusses for stabilization which is made of glued wood, floor elements and roof elements made of Kerto material, steel connectors, and wrought iron fittings. After assembling the main components, the installation work is carried out on-site by involving several subcontractors assigned by the main customer.

The design phase of projects comprises three stages i.e., conceptual phase, systems design, and detailed design. However, the involvement of designers in the early phase is less as the conceptual idea of the building has been mostly done by the customers. The company is pursuing a business-to-business approach with real estate and construction contractors as main customers. So, customers are normally approaching the company with plans and drawing details about the building. Thus, designers at the company are more focused on the structural calculations according to customer requirements and modelling of the building, rendering the calculations from a structural engineer. The overall design process has not been standardized and the work sequence is not clearly defined. Most of the process that takes place during the design phase has not been supported with appropriate methods and tools and a high degree of uncertainty has been observed as they are constantly working with unique projects. Also, there is no gate point in the design phase to evaluate the drawings and to lock the late customer changes. Individual learning takes place between the projects, while designers develop their methods to simplify their work. There is no proper documentation of ideas and knowledge since it is locked in the individual's head and is less efficient in sharing information or knowledge. For e.g.: the lack of documentation of the rules of the building system is most evident. The documentations about the rationale for design solutions were missing and designers were not aware of which considerations are required when working with specific solutions. However, they have recently started using the parametric modelling linked to the BIM tool for connection detailing to shorten the design lead time and adapt to late changes. Therefore, these findings lead to perform an in-depth study and analysis of BS support in the design process at the case company. 


\section{Analysis of building system support for design with platform assets}

To understand the use of the product platform approach in the case company, an analysis has been conducted by comparing the existing building system support available in the design process with the platform assets defined by Robertson and Ulrich [15]. It has been used as a model of analysis. The work was carried out through a set of semistructured interviews, in which the management team also participated. The support methods and tools are explicitly used by designers at different stages of the design development process, see table 1. This illustrates the connection between the support tools and methods in design phase with four platform assets, e.g. BIM tool, calculation tools, etc. can be categorised in the process assets while the custom component library, ERP, etc. comes under knowledge, as it is considered as an important support for the design of the building. From the empirical data, existing support and tools are scrutinized and potential platform assets have been identified and that are connected to the BS of the case company. However, the quantitative analysis on how good each support at present is not measured but the management and challenges concerned with these supports have been presented.

Table 1. Framework of platform assets and building system support in the design phase

\begin{tabular}{lcccc}
\hline $\begin{array}{c}\text { Support tools and methods } \\
\text { in design phase }\end{array}$ & Component & Process & Knowledge & Relationships \\
\hline BIM tool & $\mathrm{X}$ & $\mathrm{X}$ & \\
Structural calculation tools & & $\mathrm{X}$ & $\mathrm{X}$ & \\
Parametric CAD modelling & $\mathrm{X}$ & $\mathrm{X}$ & \\
Checklist & $\mathrm{X}$ & & $\mathrm{X}$ \\
Custom component library & $\mathrm{X}$ & & $\mathrm{X}$ & $\mathrm{X}$ \\
Cross functional team & & & $\mathrm{X}$ & \\
$\begin{array}{l}\text { External consultant support } \\
\text { ERP system }\end{array}$ & $\mathrm{X}$ & $\mathrm{X}$ & \\
$\begin{array}{l}\text { Cost calculation tools } \\
\text { Mock-up for testing }\end{array}$ & & $\mathrm{X}$ & \\
Clash checking & & & \\
\hline
\end{tabular}

The characteristics of the building system offering by the case company appear to be an engineer to order (ETO) with a partially defined component-based platform. This includes major components such as post, beam, floor elements, roof element, steel connectors, etc. Some sub-components have been predefined in the custom component library to support designers for modelling, e.g., floor element and roof element. However, some components are challenging that need to be designed from scratch mostly when commencing projects. It shows the uncertainty about the possibilities of reusing those for different projects as several parameters determine the design, e.g.: Connectors. A slight variation in the total load of building or dimension of the post and beam component could result in the new design. The company uses several tools for structural calculation and BIM tool (Tekla structures) during the modelling phase of the design. Within the BIM tool, a custom component library is integrated which can be used to some extent as support for project design. However, there are no finished component design solutions that can be fully reused for a project. Parametric CAD modelling has been implemented and is in the early stages of implementation and its extensive use requires further verification and validation. External consultants are assigned to support the design functions related to the installation works such as plumbing, electric, ventilation, etc. A cross-functional team and meetings are usually initiated when uncertainties occur. However, it is not routine for all projects to analyse progress and challenges. Currently, much of the data is manually transferred between different receivers and production 
equipment, resulting in extra work. Inadequate cost estimation and proposal would lead to cost and schedule overruns. Currently, the company does not use any tools to calculate the cost as part of the project proposal but uses a spreadsheet to perform calculations. However, the ERP system is available, but it is not connected to the BS or the BIM.

In summary, from a platform perspective, the building system is mainly consisting of component-based assets defined with technical details and functionality. The predefinition of process, knowledge and relationship assets at the case company seems weak and unstructured. The analysis of data shows that there is a lack of support methods for the process and knowledge asset. A project-based approach can be seen in the overall development. The design phase of the company has been identified as challenging phase on the state of practice. The lack of common standards for an efficient information exchange generates frequent rework, especially evident in the design process. Several subcontractors are involved in the process and many iterations have been carried out for the projects. Moreover, the documentation of knowledge appears to be limited, which implies that the building system cannot fully serve as a carrier of information. The main finding is that none of the building components can be produced as off-the-shelf solutions as the company act as a supplier of major building component and every project is unique in its kind. The high involvement of the customer and the architect has been considered as a challenge to the BS. Standardisation of the design phase and building system is necessary by integrating more support for the process platform. Therefore, new methods and tools are required to support the design work and to ensure that solutions can be easily produced and assembled on site. This is important to meet both standard and unique needs and to ensure that the customer-specific solutions do not go outside the boundaries of the building system or platform.

\section{Principle support solutions for the improvement of building system}

As part of prescriptive study, the overall improvement of the process in the case company initiated with the cause-effect or fishbone analysis by participating the key personals from the design phase. The root causes of the various challenges and design process inefficiencies have been discussed, mapped and analysed with the help of a fishbone diagram. Figure 1 shows the final view of the cause and effect diagram. Both common and specific issues related to the design process of building component were discussed and grouped under different main categories. The grouping of different challenges was performed with the help of participants who is having more knowledge.

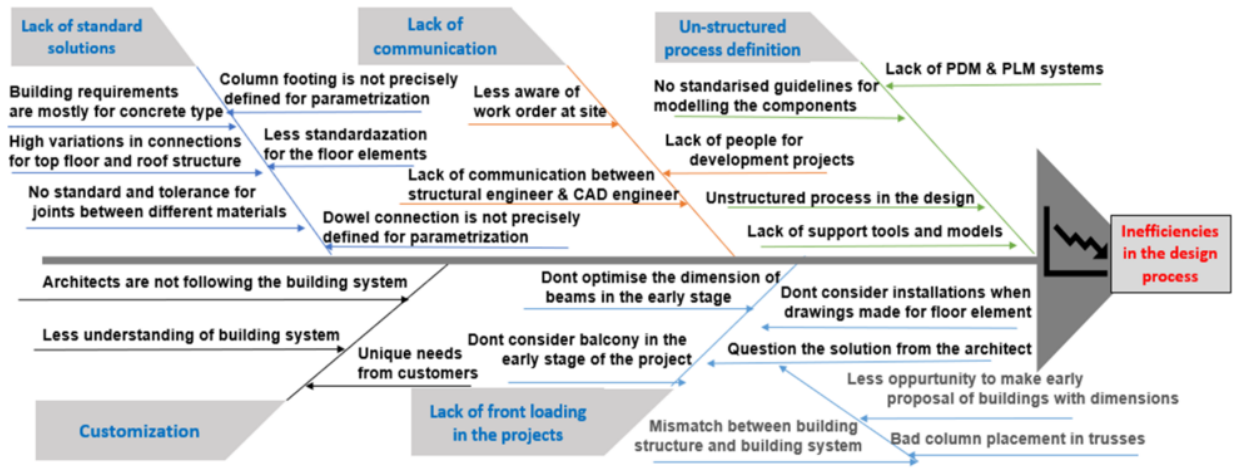

Figure 1. Cause-effect diagram 
To support the development of the platform in the company, another brainstorming session was performed to identify possible solutions to mitigate existing challenges. As a result, a methodology with principle solutions was developed which focuses more on the design process. Figure 2 shows the specific actions scrutinized from the workshop conducted with the key personals from the design department and the management team.

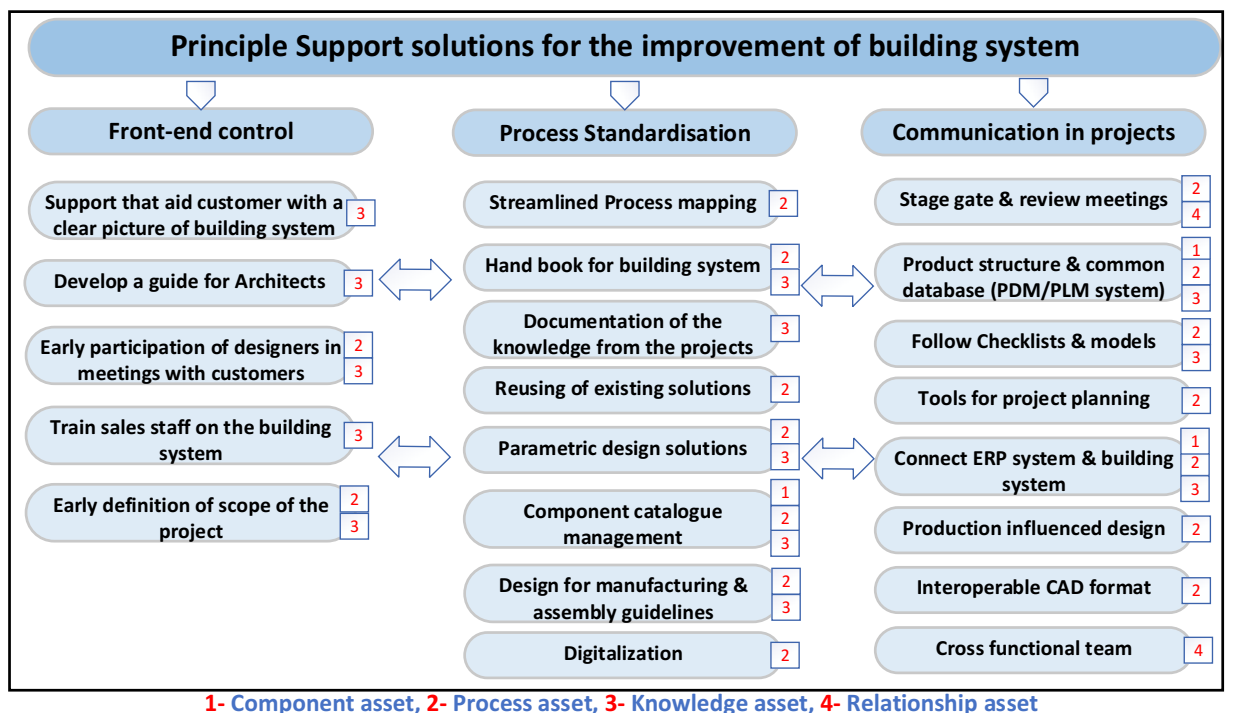

Figure 2. Methodology with principle support solutions for system improvement

The principle solutions have been ranked and categorised under three main areas that need to be improved, together with the support of the participants. The main bottleneck was found in the process and relationship assets of the company that ensued to work more focused on the process standardisation, front end process control, and information and communication. The solutions that lead to the same goal have been summarized in one section. For example, solutions listed under frond-end control could help to improve the early design issues. The solutions were discussed and prioritised together with the vision to make a concentrated effort towards a platform-based development to deliver a rational construction of multi-storey buildings. These support methods and tools can also be formalized and classified into different platform assets shown in table 1. The figure also illustrates the relationship between the different solutions and the assets of the platform. The relation of individual solutions with each of the assets defined in table 1 is marked with the number as shown in the figure. This implies that the current state of the company's platform asset (table 1) can be filled with more support solutions and it will strengthen the capability of both technical and process platforms of the BS result in the continuous improvement of the design process.

\subsection{Architect guide and Process mapping of the design process}

The company has started the improvement activities targeting the front-end control and process improvement. Subsequently, the architect guide and process mapping were initially prioritised solution from the final workshop. An example from the guide for the floor element component and its sectional view is shown in Figure 3. 


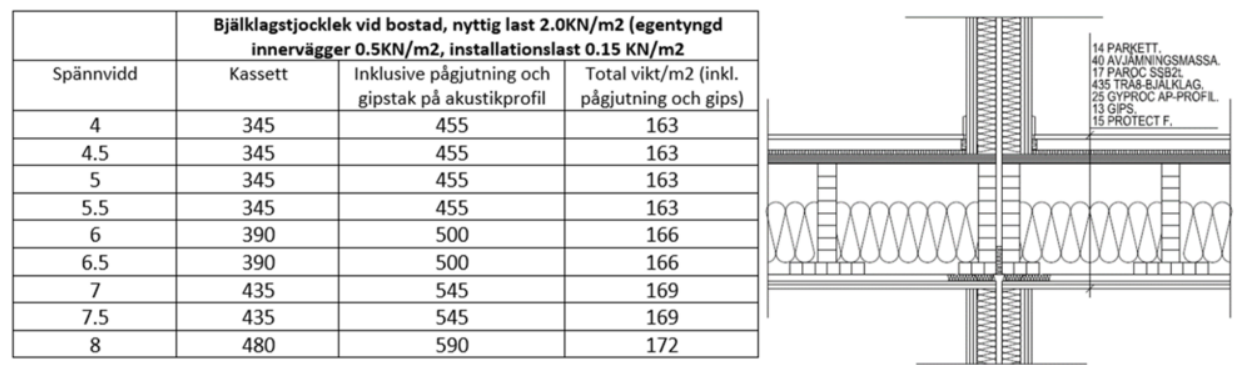

- Maximum span width of floor elements using for the building system is 8 meters

- The height of the floor element is decided by the maxi span width in the building, see table

- Direction of the floor element should be considered when designing the ventilation shafts.

- Rectangular shafts should be aligned in the same orientation as the floor element to avoid the need of extra columns in the corners of the shaft

- If installations such as ventilation and plumbing should be hidden inside the floor elements, this will in some cases add to the height of the floor element.

- The floor element cannot be used to form large round floor to floor openings.

Figure 3. Architect guide -Example of floor element sectional view and span width table

The root causes of many challenges that would appear later in the design were mostly found in the early stage of the design phase where customers and architect's involvement is enormous. This architecture guideline was established to guide the architects while using the building system for designing various types of multi-storey buildings. The purpose of this guide is to assist architects early in the design process and understand the product assortment. Designing a multi-storey building with glulam post and beam is the same as for other materials. However, there are some differences regarding the build-up of floors and walls. Also, the overall stability of the entire building needs some extra consideration as well. From a platform view, this support would enhance the knowledge asset of a building system which set a baseline in the early design. This support is crucial to realize if the needs are within the platform and can able to accomplish it cost-effectively. It will lead to a more streamlined use of the building system and definition of the scope of work even in the early stage. In addition, future work includes the development of connectors to align well with the overall approach.

The process mapping helps the design team to understand and visualise the opportunities for improvement in the design process. It has been performed together and the result was verified with the design team. During the mapping, several challenges in the design process were discussed and identified, during the mapping, where the support appearing to be less. This task helps to understand what drives the process, the inconsistencies in the current process, identify the value-adding process, alternatives ways for doing activities, etc. The mapping of detailed design processes and activities at different stages is shown in figure 4. Most bottlenecks appear in the modelling phase is shown by the dotted line in the figure, due to much involvement of numerous stakeholders in the process. The designers are the central part of the design process and several key information about technical and installation details of the building would exchange between the customers and other involved subcontractors. 


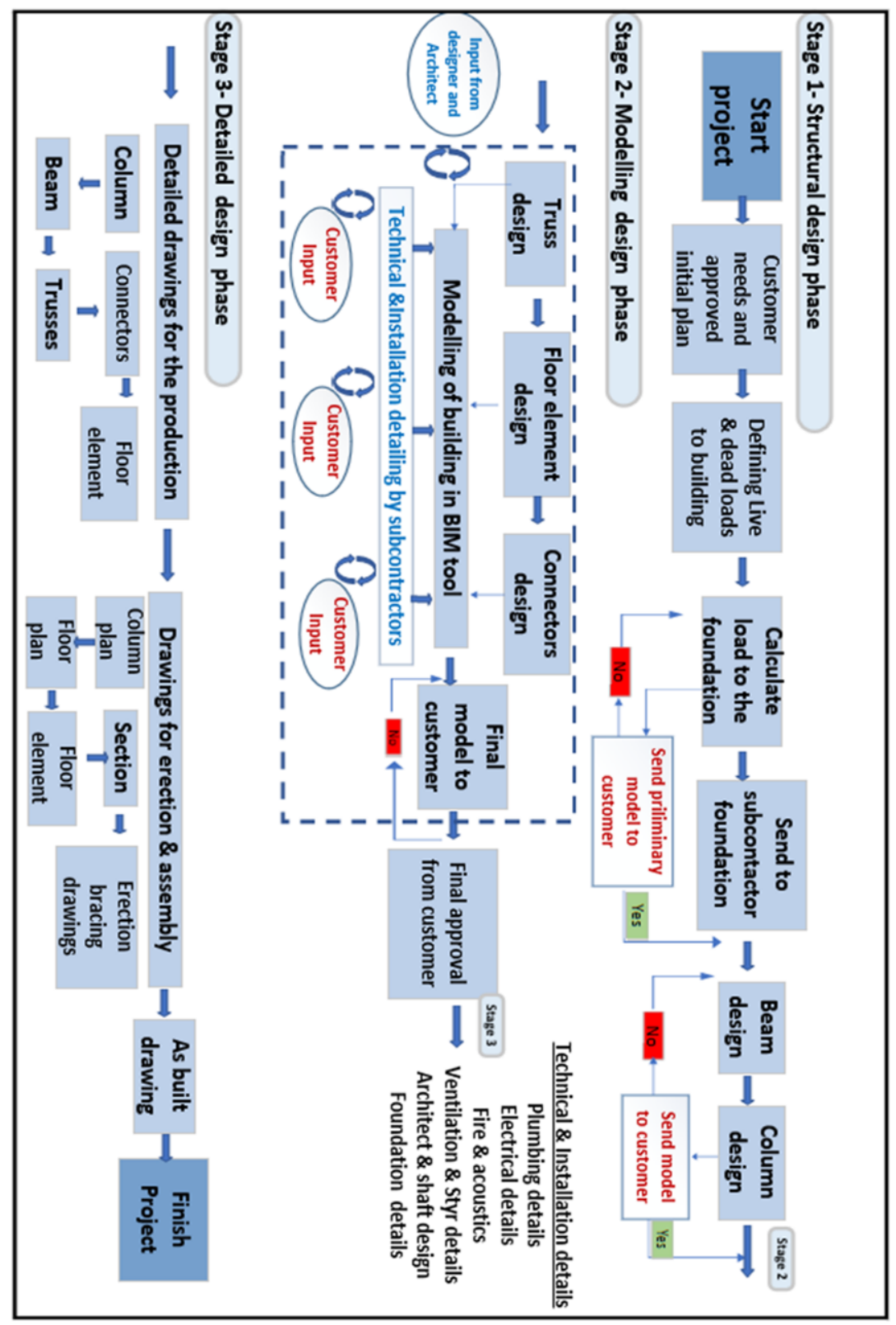

Figure 4. Detailed design process mapping at the case company

\section{Discussion}

The tension between architectural design practice and industrial construction has already been discussed by Viklund [21]. Architects are the central part of building projects and in fact, represent the voice of the customer when approaching a company. Therefore, it is important to have a clear idea about the product assortment and what is 
in the company's offer and what is not. The architecture guide exemplified can potentially solve a lot of problems that could reflect in the later stage of the design process. This is in line with the choice navigation capability explained by Salvador [18] and implies the architect guide developed by the case company. The case company does not employ an architect because of its business model and mostly they have been assigned by the customers. In fact, most of the time, designers end up with a lot of complications in the later stage of projects due to requirements resides outside the building system. Thus, a clear guide is very important for the architect in order to communicate both constraints and possibilities when using the building system [3]. This can lead to fewer surprises along the way and reduce the distance between an architectural view and designer view, where both work in the same platform to achieve a common goal. An in-depth analysis of building components shows that the company cannot have an off-the-shelf component completely as the customer needs are volatile. Housing companies can be categorised under ETO type businesses [11]. So the application of platform tools like PVM presented by Hvam [17] would not be completely possible as few parts of the building components meet the criteria for configuration or modularization principles and rest need to be engineered. Thus, it is important to analyse, if the available building components can be used to meet the customer requirements in a component-based approach that explains the solution space development [18]. This means that the designers must be aware of the components that can possibly be reused and predefine to a certain extent which is not completely conceivable for the case company. The requirements tend to change from time to time, and different approaches are necessary to fulfil them. Some components are built to be used and reused in a few applications and some are not yet existing which need more competent support to adapt to the circumstances. The company may need a combination of strategies where the components are predefined to different levels. Develop support for other components that always need engineering and design from scratch. They currently have a component library but do not manage it properly. A common library for all designers has not developed, no definition about how to use it, not all sub-components are included, etc. Standardisation of process and structuring the products enables the company to reuse the knowledge to higher degree results in the robust process design capability [18].

The findings from the study indicate that the designers interpret the building system as equal to a product platform. However, there are several important parts of platformbased development missing at present. The study verifies the lack of important assets that are not completely described in the BS to operate as more like a product platform. The company has a strong component asset, focused on technical and functionality but not fulfilling all the aspects which are relevant. The development of a fully predefined building system is not feasible for the case company. The reason is that the company mainly works as supplier and other challenges for achieving these could be (1) Volatile customer requirements prevailing (2) Less understanding of building system to Architects (3) Several stakeholders for installation design works using inoperable CAD systems (4) Unstructured development process (5) Poor information flow and communication. These are some reasons for the bottleneck in the design phase at present. Several supports that are key to the development of the project are missing. Thus, the main focus of the work was to analyse how the support for those components could be developed. The results obtained from the study could expand the current state of building system assets to a more improved future state that reinforces other platform assets, especially process, and relationship assets, see figure 4 . 
The view of the product platform concept varies from various context and the post and beam type of building system represent an ETO approach. The central part of the improvement solutions lies in the process aspects which implies that the process platform asset of the company needs more focus. Identifying and improving the existing support solutions associated with the building system is a new way of improving the overall platform-based product development. The specific solutions outlined can support and assist the designers in the calculation and modelling phase while developing standard and customer-specific products. These solutions can also help to simplify their design process, resulting in efficient production and assembly on site. However, it cannot be concluded that these listed solutions would solve all the design issues. The building system evolves based on the day to day knowledge and experiences from different projects and unforeseen customer requirements that may arise in the future. Therefore, it is important to manage the building system with the required support tools and maintain it for using it for future projects. Several solutions and improvements identified in this study would become part of the platform assets as explained. However, it is not easily classified according to Robertson and Ulrich [15] since it does not draw the whole picture for an ETO approach and focuses more on the production process than on the engineering process. To increase efficiency in the IHB design process, two possible options are recommended. Companies need to pre-define the main building components at a different level, or they must develop support methods and tools that can help generate solutions if the first option is not feasible. It is vital that the solutions must be evaluated and validated to verify that this is the best way to meet different requirements (ibid) and can be able to design and produce them with less lead time and cost. Therefore, the integration of verified methods, the exchange of knowledge between projects and the reuse of established processes in the building system reduces the uncertainties and risk of design errors. More support in the design would eventually increase the flexibility of the building system where it can effectively respond to uncertainties. The workshop participants agreed that the product platform approach and applications would bring greater variability and design freedom for the designers and, consequently the projects lead time and cost could be reduced. The development of the building system in terms of different assets seems close to the platform development defined by Robertson and Ulrich [15]. Thus, it can be concluded that the building system is possible to expand and can be considered as part of product platform. The results of this study show that the methodology would improve the internal and external efficiency of building systems.

\section{Conclusion}

The result shows that a building system in many disciplines can be considered as a part of a product platform. However, it aligns well with building systems that offer standard solutions in which the building assets are clearly pre-defined for developing solutions. By analysing the different building system supports against the platform assets defined by Robertson and Ulrich [15], it has been possible to show how building systems can be expanded into a product platform. More over, the findings reported in this article are in line with the three capabilities presented by Salvador [18]. It is used mostly as a technical platform by designers where the process platform appears weak and has limited support. However, more attention should be given to the process platform to support the existing technical platform [2] and manage both equally to achieve increased efficiency. This could be possible with the help of support methods and tools in the design phase. This 
study also illustrates a methodology with principle solutions that can be used as design support for the case company as a path forward and improve further from a platform perspective. These solutions serve as a key tool in the design development process, enabling designers to fetch support for establishing strategic development objectives. By developing specific support methods and tools for the design phase can improve the different platform assets connected to building system and could be considered for future studies. Also, the applicability of the methodology to other context need to be considered for future studies.

\section{Acknowledgement}

We would like to thank all participants from the case company for vaulable contribution, Prowood and the knowledge foundation for the financial support of this research project.

\section{References}

[1] Boverket, 2016, Reviderad Prognos Över Behovet Av Nya Bostäder Till 2025 [Uppdated Forecast of the Need for New Accomodation by 2025], Accessed: 03.12.2019. [Online]. Available: http://www.boverket.se/

[2] Lessing, J., Industrialised house-building. Concept and Processes, 2006.

[3] Söderholm, E., Applicability of continuous improvements in industrialised construction design process. 2010, Luleå tekniska universitet.

[4] Andersson, N. and J. Lessing, The Interface between industrialized and project based construction. Procedia Engineering, vol. 196, 2017, pp. 220-227.

[5] Malmgren, L., P. Jensen, and T. Olofsson, Product modeling of configurable building systems a case study. Journal of Information Technology in Construction (ITcon), vol. 16(41), 2011, pp. 697-712.

[6] Ulrich, K.T., Product design and development. 4. ed., Boston, Mass. : McGraw-Hill/Irwin, Boston, 2008.

[7] Jansson, G., H. Johnsson, and D. Engström, Platform use in systems building. Construction Management and Economics, vol. 32(1-2), 2014, pp. 70-82.

[8] Jensen, P., Configuration of modularised building systems, 2010 (Doctoral dissertation, Luleå tekniska universitet).

[9] Simpson, T.W., et al. Platform-based design and development: current trends and needs in industry. In: International Design Engineering Technical Conferences and Computers and Information in Engineering Conference, 2006, vol. 4255, pp. 801-810.

[10] Jiao, J., T. Simpson, and Z. Siddique, Product family design and platform-based product development: a state-of-the-art review. Journal of Intelligent Manufacturing, vol 18(1), 2007, pp. 5-29.

[11] Jansson, G., Industrialised housing design efficiency. 2010, Luleå tekniska universitet.

[12] Mukkavaara, J., Structures for supporting BIM-based automation in the design process. 2018, Luleå University of Technology.

[13] Olofsson, T., P. Jensen, and A. Rönneblad. Configuration and design automation of industrialised building systems, In International Conference CIB W78: 16/11/2010-18/11/2010. 2010.

[14] Bonev, M., M. Wörösch, and L. Hvam, Utilizing platforms in industrialized construction. Construction Innovation, vol. 15(1), 2015, pp. 84-106.

[15] Robertson, D. and K. Ulrich, Planning for product platforms. Sloan management review, vol 39(4), 1998, pp. 19.

[16] Jansson, G., Platforms in industrialised house-building. 2013, Luleå tekniska universitet.

[17] Hvam, L., N.H. Mortensen, and J. Riis, Product customization. 2008: Springer Science \& Business Media.

[18] Salvador, F., P.M. De Holan, and F. Piller, Cracking the code of mass customization. MIT Sloan management review, vol. 50(3), 2009, pp. 71-78.

[19] Blessing, L.T. and A. Chakrabarti, DRM: A Design Reseach Methodology. 2009: Springer.

[20] Yin, R.K., Case study research: design and methods. 1994. Thousand Oaks, CA, 1994.

[21] Viklund, E., Design approaches in industrialized house building: A creativity perspective: Ett kreativitetsperspektiv. 2017. (Doctoral dissertation, Luleå tekniska universitet). 